\title{
Correspondence
}

CH. \& WTO REV. 2017:1; 145-162

http://dx.doi.org/10.14330/cwr.2017.3.1.07

pISSN 2383-8221 • elSSN 2384-4388

China and WTO Review

\section{A Brief Review of UDRP: Achievements, Challenges and Recommendations}

\author{
Lingtong Kong*
}

\section{Introduction}

\section{A. The Establishment of UDRP}

As early as 1998, the Internet Corporation for Assigned Names and Numbers ("ICANN") was founded as "an experiment in technical self-management by the global Internet community." One of its primary management objectives was to tackle the notorious 'Trademark Dilemma.' When a trademark is used as a domain name without its owner's consent, consumers may be misled about the source of the product or service offered on the website, and trademark owners may not be able to protect their rights without very expensive litigation. ${ }^{2}$

In order to initiate a balanced and transparent process to address the Trademark Dilemma, ICANN had sought comments from the general public as well as assistance from the World Intellectual Property Organization ("WIPO"). The WIPO later suggested the establishment of a "mandatory administrative procedure concerning abusive registrations." " In response to the WIPO's suggestion, in 1999, the Uniform Domain-Name Dispute-Resolution Policy ("UDRP") ${ }^{4}$ was released and later came into effect.

\section{B. The Operation of UDRP}

UDRP provided a mandatory administrative proceeding for a third-party (usually a trademark/service mark owner) to complain about his/her trademark infringements if:

* LL.M. (UHK). The author can be contacted at: mamsds@connect.hku.hk 
1 the domain name holder's domain name is identical or confusingly similar to a trademark or service mark in which the Complainant has rights;

2 the domain name holder has no rights or legitimate interests in respect of the domain name; and

3 the domain name holder's domain name has been registered and is being used in bad faith.

A Complainant should make a complaint to an Approved Dispute Resolution Service Provider ${ }^{6}$ (hereinafter Provider). If the Provider considers that the complaint is in compliance with UDRP's requirements, it would notify the domain name holder (hereinafter Respondent) to respond in twenty days. ${ }^{7}$ Afterwards, the Provider would appoint a one- or three-member panel (Panel) based on a publicly published list of panelists. Within 14 days of the appointment, the Panel would render a decision, which has three possible outcomes: (1) Domain Name Transferred; (2) Complaint Rejected; or (3) Domain Name Cancelled. ${ }^{8}$

If the Provider is not informed that the Respondent has commenced a lawsuit against the Complainant within 10 days from when the decision was made, the decision would be implemented. ${ }^{9}$

\section{Achievements}

\section{A. A Great Success}

Being regarded by scholars as a unique, non-national, low cost dispute resolution mechanism, ${ }^{10}$ UDRP has been proved a great success in terms of both caseload and effectiveness. ${ }^{11}$ Although UDRP is not intended to be a substitute for traditional infringement or Cybersquatting litigation, it has become such in many ways. ${ }^{12}$ According to the statistics, total WIPO case filings exceeded 33,000 in 2015 , encompassing over 61,000 domain names. ${ }^{13}$ In addition, while UDRP was conceived primarily for application in the gTLDs, ${ }^{14}$ it has been increasingly adopted at the level of the ccTLDs via the Domain Name Dispute Resolution policy for country code top level domains. ${ }^{15}$ The popularity of UDRP in the ccTLDs will "introduce greater uniformity in domain name dispute resolution at the international level and therefore generate significant economies of scale, which would benefit parties, registration authorities and dispute resolution service providers alike." ${ }^{16}$ 


\section{B. Reasons of Achievements}

\section{Centralized Management Structure of the Internet}

UDRP can be successful mainly by the centralized management structure of the Internet. In a traditional court system, it is difficult to gain jurisdiction over a party in another country. ${ }^{17}$ The systematic and procedural differences between jurisdictions may cause difficulties for the infringed to initiate a lawsuit or enforce a ruling. Thanks to the Internet, however, UDRP can avoid this dilemma.

In practice, ICANN, which holds all available domain names, does not assign domain names directly to domain name holders. Instead, ICANN would examine and accredit qualified companies by signing a basket of agreements ("BA-A") with them. These qualified companies are called the ICANN-Accredited Registrars, which are entitled to accept or reject domain name registration applications on behalf of ICANN. If a person or organization (registrant) wants to apply for a domain name, s/he should make an application to an ICANN-Accredited Registrar and sign another basket of agreements ("BA-B") with it. ${ }^{18}$ In order to give mandate jurisdiction to UDRP, ICANN incorporates UDRP in BA-A. Moreover, BA-A obliges the ICANN-Accredited Registrars to incorporate UDRP in BA-B. Regarding implementation, BA-A provides that Registrars should implement the decision rendered under UDRP. ${ }^{19}$

As we can see, by utilizing this ingenious dual-layer contractual design, ICANN manages to force all domain name registrants/holders into the administrative domain name dispute proceeding without complicated legal procedure or inter-governmental cooperation. Although ICANN exerts quasigovernmental sway over the administration of the Internet, UDRP is carried out and enforced purely through a series of private contracts rather than international or national regulations. ${ }^{20}$ This mechanism avoids the time-consuming and unpredictable enforcement of foreign judgements. It makes the decision under UDRP more reliable and cost-effective.

To sum up, the centralized nature of the Internet management differentiates UDRP from other alternative dispute resolutions ("ADR") by overcoming the obstacles from jurisdiction and implementation issues. This is the reason why other ADRs without a similar centralized power to replicate UDRP. 


\section{Efficiency and Affordability}

As a mechanism against cyber-squatting, UDRP highlights the efficiency and affordability. In practice, all Providers would have an expeditious case-handling timeframe as well as a reasonable fees schedule. In the Asian Domain Name Dispute Resolution Centre ("ADNDRC"), e.g., the normal timeframe of a domain name dispute case is 45 days $^{21}$ and the total fee for a single-member panel on one domain name dispute costs only USD 1,300. ${ }^{22}$ In addition, all communications and document submissions can be done via electronic methods, which reduces the cost of international express service.

\section{Transparency}

ADNDRC, e.g., provides not only the UDRP policy, rules and supplementary rules, but also all decisions, including details of parties, arbitrators and reasoning. ${ }^{23}$ This transparent practice distinguishes UDRP from other ADRs like arbitration and mediation, in which results are usually confidential. In order to maintain such high degree of transparency, the public and professionals would supervises and scrutinize the operation, mechanism and decisions of UDRP, respectively. These systems are of great benefit to the improvement of UDRP. ${ }^{24}$

\section{Criticisms}

\section{A. Neutrality and Forum Shopping}

UDRP is largely supported by trademark owners for its finance. ${ }^{25}$ Since UDRP allows the challenger to select the dispute resolution service provider, it may cause complainants to select a Provider who is in favor of the trademark holder. ${ }^{26}$

\section{1."Bad Money Drives Out Good"}

In terms of the selection of Providers, Mueller observed a phenomenon similar to Gresham's law ${ }^{27}$ in the early cases of UDRP. ${ }^{28}$ He concluded that the WIPO Arbitration and Mediation Centre (hereinafter WIPO AMC) and National Arbitration Forum ("NAF") were the most complainant-friendly Providers. ${ }^{29}$ With win rates of complainants at about 70 percent, these two Providers handled about 400 cases a year (2001). ${ }^{30}$ On the contrary, eResolution, which had an equal win rate between complainants and respondents, only received 86 cases (Table 1). 
Table 1: Statistics about Decisions by Providers in $2001^{31}$

\begin{tabular}{l|c|c|c|c|c|c}
\hline \multirow{2}{*}{ Provider } & \multicolumn{2}{|c|}{ The WIPO } & \multicolumn{2}{c|}{ NAF } & \multicolumn{2}{c}{ eResolution } \\
\hline Respondent wins & 82 & $16.6 \%$ & 62 & $17.5 \%$ & 36 & $41.9 \%$ \\
\hline Complainant wins & 333 & $67.5 \%$ & 254 & $71.5 \%$ & 38 & $44.2 \%$ \\
\hline Terminated/settled & 78 & $15.8 \%$ & 39 & $11.0 \%$ & 12 & $14 \%$ \\
\hline Total & 493 & & 355 & & 86 & \\
\hline
\end{tabular}

Source: Compiled by the author.

Ironically, a decade and a half of case histories show that this phenomenon is in fact exaggerated. According to the latest data from the three most active Providers, the WIPO AMC, the Forum (formerly known as NAF) and ADNDRC, the win rates of the Complainant have reached a new high at 90 percent, $^{32} 92$ percent, $^{33}$ and 89 percent, $^{34}$ respectively. Meanwhile, eResolution, which gave the Respondent a better chance, describing UDRP as "corrupt" and "biased," withdrew from settling disputes and then went bankrupt. ${ }^{35}$ Its former president, Karim Benyekhlef stated:

The situation was so obvious that even the Canadian Government selected the more expensive and foreign WIPO rather than the national and cheaper service of eResolution in order to assure a more convenient outcome. ${ }^{36}$

Regarding the existence and popularity of Providers, there seems to be a form of 'natural selection' in which complainants vote with their feet. The result, however, is not "survival of the fittest," but rather "survival of the highest win rate." Since all Providers, to some extent, rely on the Complainants' patronage to support themselves, it should be reasonable to doubt that Providers may, either intentionally or unintentionally, rule in favor of complainants.

\section{Professional Background of Panelist}

It is noteworthy that there is a dichotomy between Providers and the panelists of Providers. In most cases, panelists are working part-time so that they do not rely on commissions from complainants to make a living. Their impartiality should be thus more credited. 
However, there is one large exception. Many UDRP arbitrators are trademark lawyers. As an old saying goes - "where you stand depends on where you sit" many IP lawyers may be more pro-plaintiff than other professionals. ${ }^{37}$ Therefore, many people are concerned that their personal stakes or preferences may prevent a neutral judgement. ${ }^{38}$ This is especially true in some tricky cases such as Microsoft $v$. MikeRoweSoft. ${ }^{39}$

\section{Preferences of Providers and Selection of Panelists}

Theoretically, while a panel decides the case at its own discretion, Provider has no role to play during the proceedings. In some cases, however, Providers are able to exert their influence by selecting panelists or allocating caseloads.

Despite claims of impartial random case allocation of panelists, ${ }^{40}$ during the sample period, 53 percent of all NAF single panel cases (512 of 966) was decided by only six people and the complainants' percentage of victory in those cases was an astounding 94 percent. $^{41}$

Not all Provider allocated cases are skewed in such a way, however. Table 2 observes no similar effect on the available data from ADNDRC. In 2014, top six busiest panelists in ADNDRC decided about 30 percent of the total caseload, with an average challenger's approval rate of 84 percent. This is in fact lower than the total complainants' approval rate of the ADNDRC (89 percent).

Table 2: Statistics of Panelist with the Heaviest Caseload ${ }^{42}$

\begin{tabular}{l|c|c|c}
\hline Top-Six Panelist & $\begin{array}{c}\text { DN Transferred } \\
\text { Decision }\end{array}$ & $\begin{array}{c}\text { Total } \\
\text { Decision }\end{array}$ & $\begin{array}{c}\text { Complainants } \\
\text { Success Rate }\end{array}$ \\
\hline ZHAO, Yun & 8 & 12 & $67 \%$ \\
\hline LIAN, Yunze & 8 & 9 & $89 \%$ \\
\hline WU, Yuhe & 7 & 8 & $88 \%$ \\
\hline GAO, Lulin & 7 & 8 & $88 \%$ \\
\hline LAM, Lok Fu & 7 & 7 & $100 \%$ \\
\hline LI, Yong & 6 & 7 & $86 \%$ \\
\hline Sum & $\mathbf{4 3}$ & $\mathbf{5 1}$ & $\mathbf{8 4 \%}$ \\
\hline
\end{tabular}

Source: Compiled by the author. 


\section{Brief Summary}

Given that UDRP was born to combat cybersquatting, without scrutiny on a caseby-case basis, a relatively high complainant success rate per se may not suffice to prove that Providers are biased. However, the contemporary UDRP regime leaves the opportunity for forum shopping and pro-defendant providers have been driven out.

\section{B. Consistency}

UDRP stipulates that trademark holders need to meet three requirements to get support from a panel. ${ }^{43}$ However, provisions in UDRP are brief and abstract, so that panelists are entitled great discretion "as it considers appropriate in accordance with the Policy and these Rules." diverse situations, different educational backgrounds, and interpretation of provisions or personal preferences of a panelist.

In addition, UDRP does not follow the doctrine of Precedent; decision will not bind another decisions. While some panelists tend to follow precedents, others do not. Moreover, even those panelists who prefer similar decisions may follow contradictory ones, causing divergent chains of case law with similar underlying facts. ${ }^{45}$

Conflict precedents and divergent decisions are, to some extent, related to the forum shopping issue. They would also increase the unpredictability of UDRP and impair its authority.

\section{Procedural Matters}

\section{Timeframe}

In regard to the UDRP conflict resolution, a decision shall be made in an expedited manner. It has been successfully accomplished. However, the expeditious procedure is far more likely to benefit the Complainant rather than the Respondent. ${ }^{47}$ The problem is that while trademark holders have almost unlimited time to prepare their complaints before bringing the case to a Provider, ${ }^{48}$ a Respondent usually has only 20 or a maximum of 24 calendar days ${ }^{49}$ to file a response.

Admittedly, the time limitation for a defendant to respond is an inherent prejudice in almost every dispute resolution mechanism. ${ }^{50}$ It is a matter of degree 
to balance the benefit of defendants and the expedition requirement of the adjudication mechanism. This timeframe should be enough for those experienced respondents because they are usually equipped with in-house lawyers. Twenty (20) days are not, however, enough time for those without abundant resources such as start-up IT companies or individuals to give a satisfactory response. ${ }^{51}$

UDRP's relatively high respondent absence rate on the one hand may result from cyber-squatters' own estimation that they do not have many chances of winning. On the other hand, it may be also attributed to the fact that the Respondent simply do not have enough time to react.

\section{Opportunity of Fair Hearing}

The UDRP rules make it clear that there shall be no in-person hearings (teleconference, videoconference, or web conference) unless the Panel determines, as an exceptional matter, that a hearing is necessary. ${ }^{52}$ In addition, UDRP does not provide punishment for false statements. ${ }^{53}$ The combination of these two factors may encourage some parties to lie. Considering the convenience of having video conferencing, it may be disproportionate to restrict hearings only to 'exceptional' circumstances.

\section{Evaluation on Questionable Recommendations}

For improving UDRP, many recommendations have been proposed. Some of them require radical reforms, which may introduce new problems or tilt the balance from expedition to fairness. UDRP was designed to serve three underlying purposes, namely:

1. To create global uniformity regarding cyber-squatting;

2. To reduce the cost of resolving disputes regarding cyber-squatting; and

3 . To be strictly restricted its application to the most flagrant types of cybersquatting (while other disputes would still be left to courts). ${ }^{54}$

Bearing these goals in mind, the UDRP reform should stick to its founding principles and avoid extra burdens to both parties and Providers. 


\section{A. The Selection of Providers}

In order to address the dilemma of forum shopping, scholars have proposed several recommendations about the Provider selection procedure, including random allocation and Registrar selection. ${ }^{55}$

\section{Random Selection Model}

In Random Selection, Complainants should not select Providers, but be allocated on a random basis. However, the situation between different Providers varies greatly. In 2014, e.g., the WIPO AMC solved 2,634 cases under UDRP, while ADNDRC only resolved 226, less than 10 percent of the caseload of the WIPO AMC. As a result, random selection may be unfair to more popular Providers and create inordinate backlog to those who have a smaller capacity.

An enhanced version of random selection would allow ICANN to develop some kinds of allocation system to distribute cases according to several factors. However, this centralized allocation system could not promote the competition among Providers for the best dispute resolution services. Such centralized allocation system is a de facto form of planned economy.

\section{Registrar Selection Model}

The Registrar selection supplies Provider with the right to selection of the ICANN-Accredited Registrars instead of complainants. It sounds better than the Random Selection. This model, however, would cause another problem. UDRP mainly deals with disputes related to gTLDs. In this case, a registrant can select a Registrar at their will without any restrictions in relation to its domicile or nationality. As a result, shifting the right from complainants to Registrars is in fact letting the registrants, or the potential cyber-squatters, select Providers, who does not address the problem of cybersquatting and potentially makes it even worse. The author consider this even more undesirable than the current regime.

\section{B. An Appellate Procedure}

Many scholars recommend appellate procedure in order to tackle the problem of fairness and consistency. ${ }^{56}$ It is also improper from the following perspectives.

First, appellate procedure requires extra time so that the total length of the whole proceeding may take more than twice. Although all proposals are slightly 
different, they generally advocate a larger panel, e.g., a five- or seven-member panel, as well as wider utilization of live hearings, which may sharply increase the cost of UDRP.

Second, a party files an appeal to an upper body, which is supposed to be more competent and independent. In terms of UDRP, parties can only appeal to the same Provider, who has already rendered the appeal less neutral. Moreover, proposers agree that in order to prevent the abuse of appeal procedure, some substantial requirements, such as "ostensible unfairness or procedural irregularities" be met. Who should be entitled to decide "unfairness or irregularities" in this process, however? No matter what the detailed structure is, it will always vest the Provider itself in power. In other words, if a party wants to file an appeal, it is required to convince the Provider to admit that its previous decision was wrong or its staff was incompetent in complying the UDRP procedure. It is virtually difficult.

In addition, as appeal chaser should have a relatively strong desire or estimation to win the case, there is a possibility that appealing parties, if they lose, would bring the case to a court. Since decisions under UDRP would be overridden by a court easily, establishing a brand new appeal system may be much lower than its cost.

\section{A Precedent System}

Another popular suggestion about 'consistency' is to establish a precedent system based on selected cases established by some form of 'Board" ${ }^{58}$ or 'Committee" under ICANN. If precedents are binding or de facto binding, later decisions can follow earlier ones so that all decisions would be consistent under the same or materially similar situations.

However, this proposal would also introduce a critical legal risk. What if UDRP Decision A is selected and credited as a 'binding precedent' by ICANN and it is followed by Decisions B and C, but, later on, Decision A is overturned by a court? ${ }^{60}$ In this circumstance, are Decisions $B$ and $C$ still valid and enforceable? Another problem is: If Decision B is invalidated by a US court, then is Decision A still binding? What if a Chinese court affirmed Decision $\mathrm{C}$ in the meantime?

These hypothetical situations illustrate a dilemma of a precedent system under UDRP. In fact, it connects the legality of a precedent and all the subsequent 
decisions together. If one, either the binding precedent or one of the cases following this precedent, is reversed, a chain of cases following the same precedents would become uncertain. Since decisions under UDRP are subject to courts from more than 200 jurisdictions, many of which are hostile to this kind of supra-sovereignty arbitration. A precedent system would extend the power of courts deep into the UDRP regime and create unpredictability in the ICANN policy. Therefore, a precedent system of UDRP will be undesirable under the current international jurisdiction regime.

\section{Evaluation on Favorable Recommendations}

\section{A. The 'Comments' or 'Recommendations'}

In the international community, it is not rare for competent international bodies to issue 'comments' or 'recommendations' on specific treaties or regulations, which have essentially influence on domestic legal interpretation. ${ }^{61}$

In order to maintain consistency, ICANN could issue some 'comments' or 'recommendations' periodically. Some of them can be binding while others, persuasive. On its face, the 'comments' or 'recommendations' are working similarly like a precedent system since both of these target inconsistency and forum shopping. The 'comments' or 'recommendations' are more desirable than a precedent system for the following two reasons. First, these general rules will not be the subject of litigation. Since every case decided under general rules is separate, even if one decision is overturned, the underlying reasoning behind it can still be available so that other cases following the same rule would not be influenced. Second, a precedent system usually exists between unified jurisdictions sharing common legal educational background and judicial traditions. In terms of UDRP, given the sheer number and diverse backgrounds of panelists as well as different nuances between languages and wordings, maintaining a set of compatible precedents may be much more difficult than issuing 'comments' or 'recommendations.'

In fact, this practice has been well adopted by some advanced Providers. Based on the 7,000 UDRP cases, e.g., the WIPO AMC firstly released its "WIPO Overview of WIPO Panel Views on Selected UDRP Questions" in 2005. ${ }^{62}$ Its newer version, the "WIPO Overview 2.0" was compiled and published in $2011^{63}$ 
including the latest decisions. This would be a recommended practice for other Providers and ICANN to consider adopting. ${ }^{64}$

\section{B. The Diversification of Panelist}

The list of panelists should include a balanced ratio of law professors, judges, arbitrators, IP lawyers and other competent persons. In addition, there should be positions for civil liberty lawyers or staff of NGOs like the Electronic Frontier Foundation. ${ }^{65}$ For three-arbitrator panel cases, e.g., it is better to have panelists with diverse backgrounds. Providers are also recommended to publicize their case allocation mechanism as well as detailed statistics regarding relationships between panelists and their decisions, ${ }^{66}$ which would allow the public to easily scrutinize the UDPR mechanism.

\section{The Extension of Response Timeframe and Utilization of Live Hearings}

The extension of response timeframe for Respondents and the utilization of live hearings may be measures to strike the balance between fairness and efficiency with little additional cost.

The current response time limitation is twenty days. ICANN should consider prolonging this timeframe. Froomkin suggested 60 days, ${ }^{67}$ which is agreed with the author. Also, UDRP provides that it should only be conducted, subjected to panel's discretion, in 'exceptional matter[s]. ${ }^{68}$ This provision renders the live hearings a dead letter. ${ }^{69}$ Based on the development of technology, live hearings would not burden parties or panelists seriously. Live hearings or in-person hearings should be allowed whenever a panel deems it necessary or both parties agree to do so.

\section{Conclusion}

To sum up, UDRP, as a mechanism addressing cybersquatting, has already achieved great success. Its important advantage is the centralized Internet management structure, realizing a wide jurisdiction without much effort.

UDRP, however, has some flaws, including the potential lack of neutrality, consistency and fairness. ${ }^{70}$ The author would suggest that any improvements adhere to the policy's own characteristics without great cost or causing new 
problems. There are four recommendations as follows: the publication of comments, the diversification of the pool of panelists, the extension of response timeframe, and the utilization of live hearings. These proposals are consistent with the fundamental purpose of UDRP. They would solve the aforementioned flaws to a large extent.

\section{REFERENCES}

1. H. Vitzthum, ICANN: Structure and Issues ICANN: Structure And Issues (2001).

2. Statement of Policy on the Management of Internet Names and Addresses, National Telecommunications and Information Administration (1998), available at https://www.ntia. doc.gov/federal-register-notice/1998/statement-policy-management-internet-names-andaddresses (last visited on Feb. 9, 2017).

3. See The Management of Internet Names and Addresses: Intellectual Property Issues on April 30, 1999, WIPO Report, available at http://www.wipo.int/export/sites/www/amc/en/docs/ annex09.pdf (last visited on Feb. 9, 2017).

4. ICANN, Uniform Domain-Name Dispute-Resolution Policy, available at https://www.icann. org/resources/pages/help/dndr/udrp-en (last visited on Feb. 9, 2017).

5. UDRP §4(a)

6. Dispute Resolution Service Providers are approved by ICANN to accept complaints. As of 2016, there are five Approved Dispute Resolution Service Providers, namely the Asian Domain Name Dispute Resolution Centre, the National Arbitration Forum, the WIPO, the Czech Arbitration Court Arbitration Center for Internet Disputes and the Arab Center for Domain Name Dispute Resolution. For details, see the official website of ADONDRC, available at https://www.adndrc.org/mten/hken/UDRP_form.php?st=3 (last visited on Feb. 9, 2017).

7. UDRP §5, available at https://www.icann.org/resources/pages/udrp-rules-2015-03-11-en (last visited on Feb. 9, 2017).

8. There are several exceptions in the final result such as the case being withdrawn or settled between parties. See UDRP $\S \S 4$ (d), 16 \& 19 (c).

9. UDRP $\S 4(\mathrm{k})$.

10. G. Kaufmann-Kohler \& T. Schultz, Online Dispute Resolution: Challenges for Contemporary Justice (2004).

11. D. Vaver, Intellectual Property Rights: Critical Concepts in Law (2006).

12. L. Sharrock, The Future of Domain Name Dispute Resolution: Crafting Practical International Legal Solutions from within the UDRP Framework, 51 DukE L. J. 817 (2001).

13. WIPO, Cybersquatting Cases Up in 2015, Driven by New gTLDs (2016), available at http:// 
www.wipo.int/pressroom/en/articles/2016/article_0003.html (last visited on Feb. 9, 2017).

14. A Generic Top Level Domain (gTLD) is an Internet domain name extension with three or more characters. It is one of the categories of the top level domain (TLD) in the Domain Name System (DNS) maintained by the Internet Assigned Numbers Authority. gTLD includes: .com, .info, .net and .org.

15. Country Code Top-Level Domains (ccTLDs) are two-letter Internet top-level domains (TLDs) specifically designated for a particular country, sovereign state or autonomous territory for use to service their community. ccTLD includes: .cn, .kr and .hk. See WIPO, The Uniform Domain Name Dispute Resolution Policy: Background and Current Status, available at $\mathrm{http}: / / \mathrm{www} . w i p o . i n t /$ edocs/mdocs/sct/en/sct_s1/sct_s1_2.pdf (last visited on Feb. 9, 2017).

16. See ccTLD Best Practices for the Prevention and Resolution of Intellectual Property Disputes, ccTLD Best Practices for the Prevention and Resolution of Intellectual Property Disputes (2001), available at http://www.wipo.int/amc/en/domains/bestpractices/ bestpractices.html (last visited on Feb. 9, 2017).

17. L. Falzone, Playing the Hollywood Name Game in Cybercourt: The Battle over Domain Names in the Age of Celebrity-Squatting, 21 Loyola L.A. Ent. L. Rev. 320 (2001), available at $\mathrm{http} / /$ digitalcommons./mu.edu/cgi/viewcontent.cgi?article=1419\&context=elr (last visited on Feb. 9, 2017).

18. Pamela Wong, Where to File - Strategic Considerations When Filing Your Domain Dispute, J. Contemp. Legal Issues 553-7 (2000).

19. ICANN, 2013 Registrar Accreditation Agreement, available at https://www.icann.org/ resources/pages/approved-with-specs-2013-09-17-en (last visited on Feb. 9, 2017).

20. Dan Parisi, Plaintiff, v. Netlearning, Inc., Defendant (2001). 139 F.Supp.2d 745 (2001).

21. ADNDRC, Flow Chart of Proceedings, available at http://www.adndrc.org/mten/udrp_ chart.php (last visited on Feb. 9, 2017).

22. ADNDRC Domain Name Dispute Supplemental Rules art. 15(3), available at http://www. adndrc.org/mten/img/pdf/Supplemental_Rules_26-07-2012_en.pdf (last visited on Feb. 9, 2017).

23. P. Diéguez, Online Dispute Resolution for Consumers in the European Union (2011).

24. J. Hornle, The Uniform Domain Name Dispute Resolution Procedure: Is Too Much of a Good Thing a Bad Thing?, 11 SMU ScI. \& TeCH. L. Rev. 253 (2008).

25. J. Diéguez, An analysis of the UDRP experience - Is it time for reform?, 24 COMPUTER L. \& SECURity Rev. 349-59 (2008).

26. M. Mueller, Rough Justice: An Analysis of ICANN's Uniform Dispute Resolution Policy (2001), available at http://ccent.syr.edu/wp-content/uploads/2014/05/roughjustice.pdf (last visited on Feb. 9, 2017).

27. Gresham's Law, Investopedia (2010), available at http://www.investopedia.com/terms/g/ greshams-law.asp (last visited on Feb. 9, 2017). 
28. Id. at 26

29. Id.

30. Id.

31. Id.

32. WIPO, Case Outcome by Year(s) (Breakdown), available at, http://www.wipo.int/amc/en/ domains/statistics/outcome.jsp (last visited on Feb. 9, 2017).

33. See Forum Domain Name Filings Hold Steady While Portfolio of Products Expands under Updated Brand, Forum, available at http://www.adrforum.com/news\#Item2574 (last visited on Feb. 9, 2017).

34. ADNDRC 2014 Annual Report, available at http://www.adndrc.org/mten/img/pdf/Annual_ Report/ADNDRC_Annual_Report_2014.pdf (last visited on Feb. 9, 2017).

35. See eResolution leaves worldwide domain name dispute resolution behind, eResolution, available at http://www.dnso.org/clubpublic/nc-udrp/Arc00/msg00230.html (last visited on Feb. 9, 2017).

36. Supra note 23.

37. J. Gilson et al., Gilson on trademarks (2009).

38. K. Komaitis, The Current State of Domain Name Regulation: Domain Names as Second Class Citizens in a Mark-Dominated World (2012).

39. Teen fights to keep MikeRoweSoft.com, CNN (2004), available at http://edition.cnn. com/2004/TECH/internet/01/20/rowe.fight (last visited on Feb. 9, 2017).

40. Email from Tim Cole, Assistant Director of Arbitration, NAF, re-cited from M. Geist, Fair. com?: An Examination of the Allegations of Systemic Unfairness in the ICANN UDRP, available at http://aix 1.uottawa.ca/ geist/geistudrp.pdf (last visited on Feb. 9, 2017).

41. Geist, $i d$.

42. Statistics is available at https://www.adndrc.org/mten/UDRP_Decisions.php?st=3 (Remark: the website only has this table and I counted these entries one by one).

43. UDRP $\S 4(a)$. They are: (i) your domain name is identical or confusingly similar to a trademark or service mark in which the complainant has rights; (ii) you have no rights or legitimate interests in respect of the domain name; and (iii) your domain name has been registered and is being used in bad faith.

44. Rules for Uniform Domain Name Dispute Resolution Policy, art. 10(a). For details, see supra note 12, at 817-49 (2001).

45. P. Kelley, Emerging Patterns in Arbitration under the Uniform Domain-Name DisputeResolution Policy, 17 Berkeley Tech. L. J. 181-204 (2002), available at http://scholarship. law.berkeley.edu/cgi/viewcontent.cgi?article $=1347 \&$ context $=$ btlj (last visited on Feb. 9, 2017).

46. D. Wotherspoon \& A. Cameron, Reducing Inconsistency in UDRP Cases, 2 CAN. J. L. \& TECH. (2003).

47. B. Thornburg, Fast, Cheap \& Out of Control: Lessons from the ICANN Dispute Resolution 
Process, 6 Computer L. Rev. \& Tech. J. 89-329 (2002).

48. In fact, the author has interviewed a staff member from the secretariat of ADNDRC. She said that usually Complainants are well prepared and will hire experienced attorneys to represent them, while the preparations of Respondents are significantly less sufficient.

49. Rules for Uniform Domain Name Dispute Resolution Policy, art. 5(a) \& (b).

50. Supra note 24, at 272-3.

51. A. Froomkin, ICANN's 'Uniform Dispute Resolution Policy' - Causes and (Partial) Cures, 67 BrooKlyn L. Rev. (2002), available at https://ssrn.com/abstract=2718986 (last visited on Feb. 9, 2017).

52. UDRP $\S 13$.

53. Supra note 47.

54. P. Segal, Attempts to Solve the UDRP's Trademark Holder Bias: A Problem that Remains Unsolved despite the Introduction of New Top Level Domain Names, 23 J. Conflict Resolution 2-5 (2001), available at http://www.cojcr.org/vol3no1/notes02.html (last visited on Feb. 9, 2017).

55. Supra note 26.

56. Supra note 47. See also Yun Zhao, Reflection on the Finality of Panel's Decisions in Domain Name Dispute Resolution Process, With Reference to China 's Practice, 26 John Marshall J. Information Tech. \& Privacy L. (2009), available at http://scholarship.law. berkeley.edu/cgi/viewcontent.cgi?article=1347\&context=btlj; supra note 26; Ying Ding \& Yanna Gong, UDRP: Achievements and Challenge of 15-year Implementation, INTELL. PROP. 16-23 (2014), available at http://www.cnki.com.cn/Article/CJFDTotal-ZSCQ201408004. htm (all last visited on Feb. 9, 2017).

57. Zhao, id.

58. O. Armon, Is This as Good as It Gets?: An Appraisal of ICANN's Uniform Domain Name Dispute Resolution Policy (UDRP) Three Years after Implementation, 22 Rev. Litigation 100-1 (2003).

59. Zhao, supra note 56.

60. Although the 10-day grace period is elapsed, as long as limitation of actions are not spent, it is still possible for a court to scrutinize the decision.

61. See, e.g., Human Rights Treaty Bodies - General Comments, United Nations Human Rights Office of the Hogh Commissioner, available at http://www.ohchr.org/EN/HRBodies/Pages/ TBGeneralComments.aspx (last visited on Feb. 9, 2017).

62. WIPO, WIPO Overview of WIPO Panel Views on Selected UDRP Questions, Original Edition (Superseded by WIPO Overview 2.0), available at http:/www.wipo.int/amc/en/ domains/search/oldoverview (last visited on Feb. 9, 2017).

63. Id.

64. ADNDRC has started to compile and publish its own version of 'case overview' recently. It is expected to be release in mid-2017. 
65. Supra note 51.

66. D. Lametti, The Form and Substance of Domain Name Arbitration, 7 Lex Electronica (2002).

67. Id. at 62 .

68. UDRP $\S 13$.

69. In the history of ADNDRC's Hong Kong Office, no live hearings have ever been conducted among thousands of the UDRP cases it has handled.

70. There are many flaws of the UDRP, however, given the situation that: (1) UDRP highly values expedition; (2) UDRP only aims to combat the most flagrant cybersquatting; and (3) UDRP is only contractually binding and can be easily overridden by any court. 
